\title{
Post-pneumonectomy and post-lobectomy syndromes: case series and review of the literature
}

\author{
Grigoris Stratakos', Vlassis Vitsas', Nikos Koufos', Charalampos Zissis², \\ Philip Emmanouil1, Nikos Koulouris'
}

\author{
1 First Respiratory Medicine Department, National and Kapodistrian University of Athens, \\ "Sotiria" Chest Hospital, Athens
}

2 Thoracic and Cardiovascular Surgery Department, "Evangelismos" Hospital, Athens, Greece

\begin{abstract}
The post-pneumonectomy syndrome is a rare complication consisting of rotation and herniation of the mediastinal structures, the remaining lung and the respective bronchi, into the contralateral hemithorax. This situation may produce symptomatic airway obstruction and varies in its presentation and severity. We describe one case of right and one of left pneumonectomy syndrome as well as one case
\end{abstract}

Corresponding author: Nikos Koufos MD, First Respiratory Medicine Department, National and Kapodistrian University of Athens "Sotiria" Chest Hospital, Mesogeion 152, 11527 Athens, Greece.

Tel. +30.2 .107763448 - Fax +30.2 .109117710 .

E-mail:koufos_nikos@hotmail.com

Key words: Pneumonectomy; lobectomy; airway obstruction; bronchoscopy.

Authors' contribution: GS, substantial contributions to the work conception or design, work drafting and critical revision for important intellectual content, final approval of the version to be published, ensuring that questions related to the accuracy or integrity of any part of the work were appropriately investigated and resolved; VW, NKoufos, PE, work drafting and revision, substantial contributions to the work design; CZ, substantial contributions to the work design, ensuring that questions related to the accuracy or integrity of any part of the work were appropriately investigated and resolved; NKoulouris, final approval of the version to be published, ensuring that questions related to the accuracy or integrity of any part of the work were appropriately investigated and resolved.

Disclosures: There are no conflicts of interest or disclosures for none of the authors of the current study.

Informed consent: Informed consent was obtained from all individual participants included in the study.

Received for publication: 10 January 2017

Accepted for publication: 24 March 2017

(C) Copyright G. Stratakos et al., 2017

Tipografia PI-ME Editrice, Italy

Monaldi Archives for Chest Disease 2017; 87:810

doi: $10.4081 /$ monaldi.2017.810

This article is distributed under the terms of the Creative Commons Attribution Noncommercial License (by-nc 4.0) which permits any noncommercial use, distribution, and reproduction in any medium, provided the original author(s) and source are credited. of post-lobectomy syndrome. We review the literature on the pathophysiology, the clinical, radiological and bronchoscopic characteristics of this rare entity and discuss all available therapeutic alternatives.

\section{Introduction}

Post-pneumonectomy syndrome (PPS) is a rare complication, which results from extreme shift and rotation of the mediastinum after pneumonectomy (counterclockwise after right pneumonectomy or clockwise after left pneumonectomy). Rotation of the heart and great vessels and herniation of the remaining lung and main stem bronchus into the contralateral hemithorax, may produce symptomatic airway obstruction. Similar complications may occur even after lobectomy (post lobectomy syndrome - PLS) although in that case anatomical and functional changes are less prominent.

PPS has been described in children as well as in adults. Clinically, patients may present with progressive dyspnea, stridor and/or recurrent pulmonary infections. Symptoms may occur several months to many years after pneumonectomy. The diagnosis is established after evaluation of the medical history and symptoms, the radiological and bronchoscopic findings during different respiratory manoeuvres (dynamic bronchoscopy) [1].

In this report, we describe two characteristic cases of PPS (one after right and one after left pneumonectomy) and one case of PLS (right upper lobectomy), revealing their distinct pathophysiology, their variable clinical, radiological and bronchoscopic characteristics as well as reviewing the literature regarding the described therapeutic management and treatment alternatives.

\section{Case \#1}

\section{Post-right pneumonectomy syndrome}

A 70-year-old male ex-smoker (50 pack/year), presented with a recent increase in long standing exertion dyspnea, cough, wheezing, recurrent infections and inability to clear secretions during the last 6 months. He had a right pneumonectomy 2 years prior to presentation due to non-small cell lung cancer (NSCLC). A chest CT scan (Figure 1A) confirmed a counter clockwise shift of the mediastinum, herniation and stenosis of the left main bronchus. Clinical examination revealed hypoxemia, decreased breath sounds of the right hemithorax and wheezing. He was unable to perform the manoeuvres for pulmonary function tests (PFTs). Dynamic bronchoscopy under conscious sedation, revealed crescent type bronchomalacia of the remaining main stem bronchus (Figure 1B). 
Following interdisciplinary discussions, the patient was considered too compromised to undergo a corrective surgery, and intermittent noninvasive mechanical ventilation (NIMV) was applied. Two months later and while compliant with NIMV, the patient developed deteriorating exertional dyspnea. He was admitted to a regional hospital where he was offered the option of stent insertion for the management of his bronchomalacia. A fully covered self-expandable metallic stent AERO $^{\text {TM }}$ (Alveolus, Inc., Charlotte, NC, USA), $12 \times 40 \mathrm{~mm}$ in dimensions was inserted. The patient reported worsening of his cough, dyspnea and inability to clear secretions. He was transferred to our unit in a severely compromised state with sepsis and respiratory insufficiency.

Rigid bronchoscopy revealed a complicated, migrated and partly obstructed stent. It was removed and replaced by a silicone "Dumon" stent $14 \times 40 \mathrm{~mm}$ which was inserted in the left main bronchus, fully reestablishing airway patency and normal breathing (Figure 1C). After this intervention the patients' symptoms improved and NIMV was discontinued. The patient returned home. Six months later he was re-admitted for a severe pulmonary embolism episode and passed away during that hospitalization.

\section{Case \#2}

\section{Post-left pneumonectomy syndrome}

A 27-year-old female patient presented with a recent increase in dyspnea upon exercise and non-productive cough following an upper respiratory infection. She denied fever, rigors or other symptoms. The patient had undergone a left pneumonectomy 4 years before presentation due to an endobronchial carcinoid of the left secondary carina.

Chest CT scan revealed a clockwise mediastinal shift along with hyperinflation and herniation of the right lung into the contralateral hemithorax (Figure 2). The patient denied a history of recurrent infections. No additional sounds (wheezing, stridor) were heard during auscultation.

The PFTs revealed mildly reduced $\mathrm{FVC}$ and $\mathrm{FEV}_{1}(69 \%$ and $65 \%$, respectively) and a normal FEV1/FVC ratio, compatible with restrictive ventilatory dysfunction due to prior pneumonectomy. Bronchoscopy revealed mild excessive dynamic airway collapse (EDAC) during expiration without signs of tracheobronchomalacia.

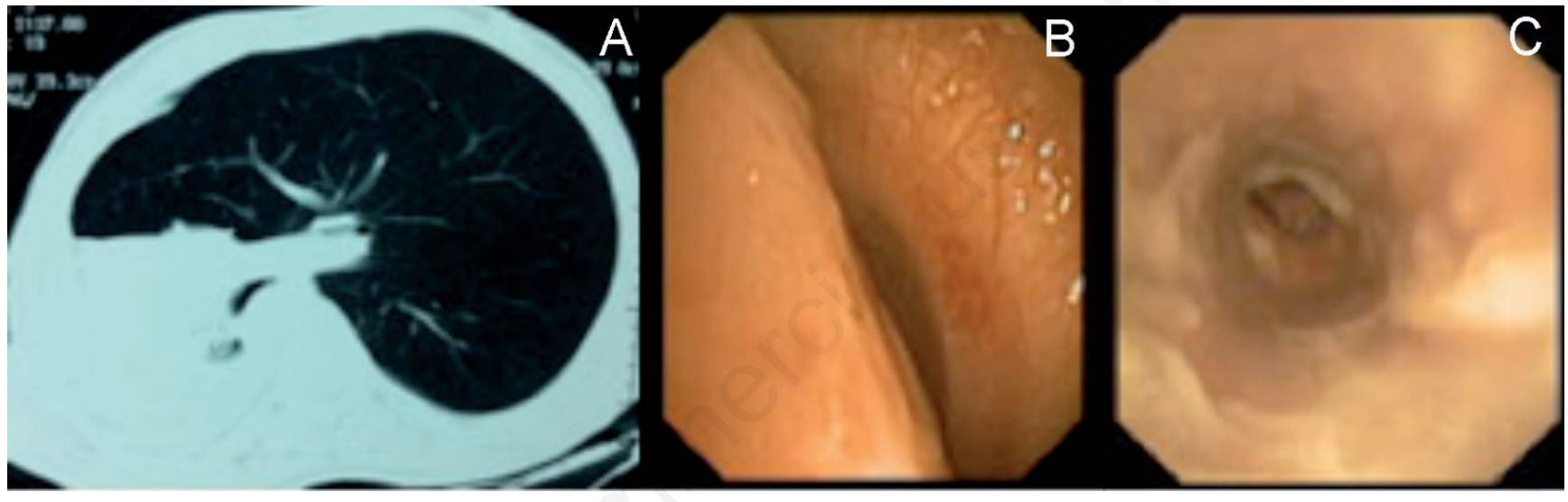

Figure 1. A) Right Post-Pneumonectomy syndrome - Thorax CT scan, counter clockwise shift of the mediastinum, herniation and stenosis of the left main bronchus. B) Development of secondary, severe, crescent type bronchomalacia of the left main stem bronchus. C) Endoscopic image inside the Novatech DUMONTM bronchial stent lumen, successfully inserted in the left main bronchus re-establishing airway patency.

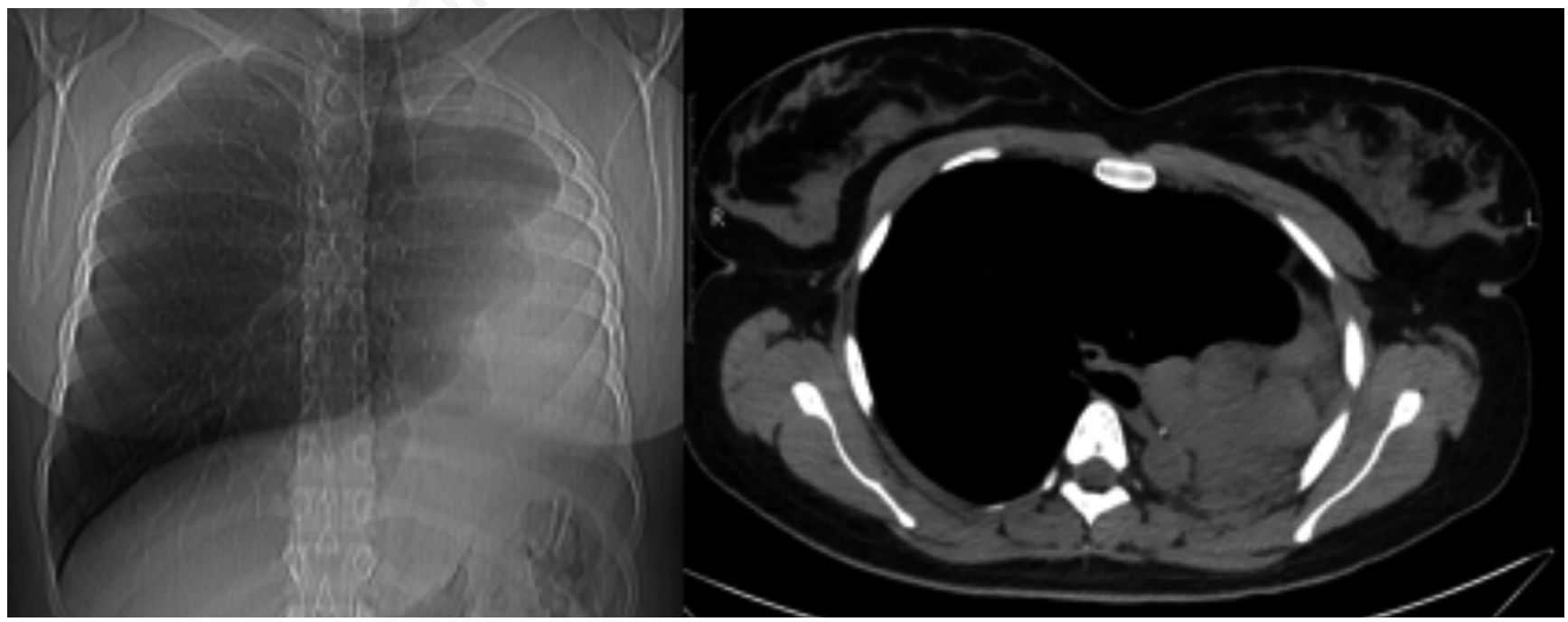

Figure 2. Chest x-ray and thorax CT scan of Post left pneumonectomy. Clockwise mediastinal shift, with hyperinflation and herniation of the right lung into the contralateral hemithorax and stenosis of the right main bronchus. 
Following treatment of her upper respiratory infection she was free of symptoms and reported improved quality of life; thus, after interdisciplinary discussions, no surgical or other interventional treatment strategy was proposed to this patient.

\section{Case \#3}

\section{Post lobectomy syndrome}

A 75-years-old male patient with a history of right upper lobectomy for NSCLC four years before encounter, presented with wheezing, chest tightness and recurrent pulmonary infections. A chest CT scan revealed a slight shift and counterclockwise rotation of the mediastinum (Figure 3A). The dynamic bronchoscopy revealed localized inflammation with bronchomalacia and excessive dynamic airway collapse of the bronchus intermedius. The presence of a surgical stitch remnant was noted at the site of the bronchial stump and removed. Although the patient improved after the initial bronchoscopy, followed by a course of antibiotics, he relapsed with recurrent episodes of bronchitis, dyspnea, stridor and inability to clear secretions. A self-expandable metallic stent (aero stent $12 \times 40 \mathrm{~mm}$; Alveolus, Inc.) was inserted in the bronchus intermedius after which his clinical situation improved.

Six months later following a new episode of acute bronchitis, the stent migrated proximally and required removal. A follow-up dynamic bronchoscopy on NIMV mask proved that the narrowing of the malacic part of bronchus intermedius was corrected under positive pressure ventilation and patency was almost completely re-established (Figure 3 $\mathrm{B}, \mathrm{C})$. Taking into consideration his age, previous stent migration, and symptoms, it was decided that non-invasive mechanical ventilation was an optimal treatment option for his bronchomalacia. The patient has been on NIMV since (for 24 months) and follow up clinical evaluation revealed improved quality of life.

\section{Discussion}

The term PPS was first introduced in 1979 by Wasserman et al. [2]. It is a rare syndrome which is estimated to occur with an incidence of 1 in 650 pneumonectomies [3]. It occurs more commonly in young patients possibly due to increased elasticity and compliance of the remaining lung and bronchial tree. Secondary bronchomalacia may develop over time which occurs presumably due to prolonged compression of the cartilaginous rings between a great vessel and the vertebral bodies. Typically, the syndrome is more frequent and more severely symptomatic after right pneumonectomy due to the compression of the left mainstem bronchus between the spine and aorta posteriorly and the pulmonary artery anteriorly [3,4]. In more recent reports, cases of PPS after left pneumonectomy have also been demonstrated especially in patients with right sided aortic arch although in general they present with minor clinical gravity [3-5].

In order to diagnose PPS one must first exclude other reasons of dyspnea such as recurrence of primary disease, pulmonary hypertension, thromboembolism, heart failure. This condition can be accompanied by excessive dynamic airway collapse (EDAC), which is a discrete condition referring to the excessive movement of the membranous part of the trachea or main stem bronchi, producing a dynamic airway narrowing during expiration or cough while the anterior cartilaginous wall remains intact or tracheobronchomalacia characterized by flaccidity of the anterior wall cartilage [6,7]. Patients with secondary bronchomalacia after a pneumonectomy are often misdiagnosed and treated for long periods of time as asthma or COPD before the diagnosis of PPS is established [5-8]. Dynamic bronchoscopy assessment, sometimes under NIMV, is warranted to fully observe the airway collapse and plan interventional management.

Due to the rarity and the heterogeneity of patients with PPS, there are not enough large studies regarding effective treatment. We performed a review of the literature focusing on the currently used therapeutic management options and treatment alternatives. Eighty-two patients were found reported overall (Table 1).

The largest series available, included 20 patients and 18 patients respectively, submitted to surgical treatment with repositioning of the mediastinum with placement of prostheses and tissue expanders in the respective hemithorax $[8,9]$. In another series of 10 patients treated with the placement of tissue expanders, $90 \%$ of them achieved significant improvement without perioperative mortality [10]. However, in published case reports the treatment remains individualized according to the severity of symptoms, age, general condition and morphology of the underlying disease [11,12]. As a principle, the PPS course after left pneumonectomy is mild, the symptoms are not strenuous and conservative treatment can be adequate, as in our reported case. On the other hand, the PPS after right pneumonectomy is usually symptomatic and challenging regarding its management. Tracheobronchomalacia is usually an indicator of a poor outcome.

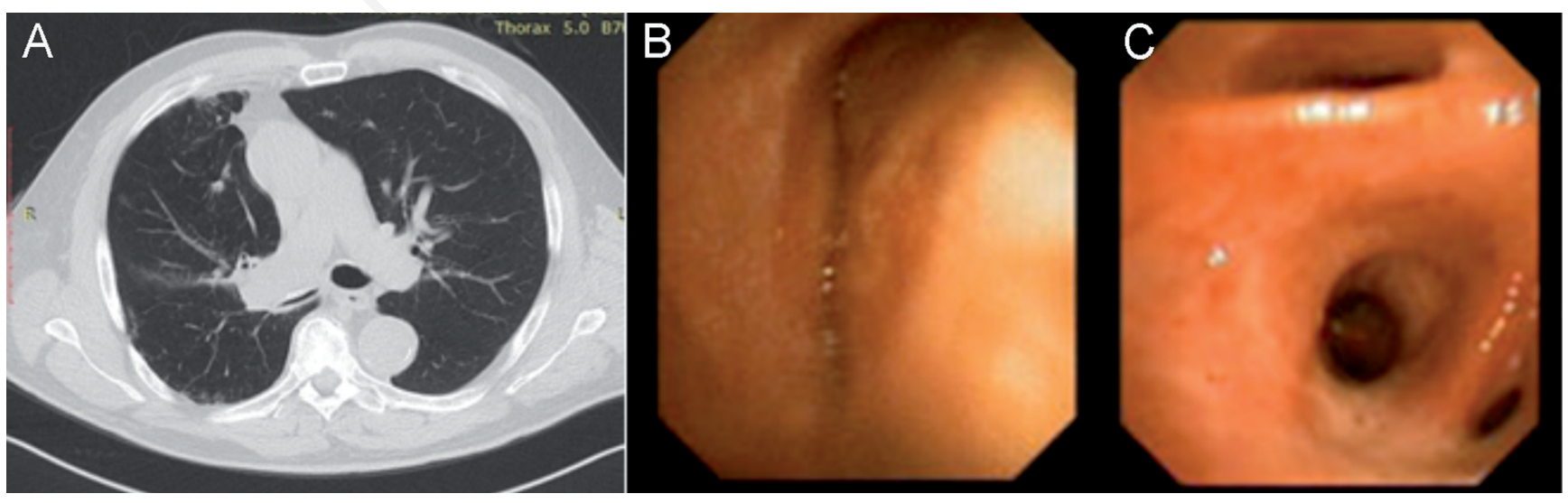

Figure 3. A) Thorax CT scan showing slight shift and narrowing of the bronchus intermedious. B) Bronchoscopy performed under NIMV mask - narrowing of bronchus intermedius. C) Bronchoscopy performed under NIMV mask - narrowing of bronchus intermedius corrected under positive pressure ventilation and airway patency re-established. 
Table 1. Reported Cases of PPS with interventional management.

\begin{tabular}{|c|c|c|c|c|c|c|c|c|}
\hline Study & $\begin{array}{c}\text { No of } \\
\text { pts }\end{array}$ & $\begin{array}{l}\text { R } \\
\text { pneumonec- } \\
\text { tomy }\end{array}$ & $\begin{array}{l}\text { L } \\
\text { pneumonec- } \\
\text { tomy }\end{array}$ & $\begin{array}{c}\text { Interval }(y) \\
\text { median } \\
(\text { min-max) }\end{array}$ & Treatment & $\begin{array}{l}\text { Compli- } \\
\text { cations } \\
\%\end{array}$ & $\begin{array}{l}\text { Mort- } \\
\text { ality } \\
\%\end{array}$ & $\begin{array}{l}\text { Improve- } \\
\text { ment } \\
\%\end{array}$ \\
\hline $\begin{array}{l}\text { Grillo } \\
1992\end{array}$ & 11 & 7 & $\begin{array}{l}4 \text { all with } \\
\text { right sided } \\
\text { aortic arch }\end{array}$ & $2(0.5-20)$ & $\begin{array}{l}\text { Mediastinum repositioning by surgical interventions } \\
\text { with or without inserting breast prostheses }\end{array}$ & 54.5 & 27 & 45 \\
\hline $\begin{array}{l}\text { Cordova } \\
1996\end{array}$ & 1 & 0 & 1 & 1.0 & $\begin{array}{l}\text { Tracheobronchial stent in right main stem bronchus } \\
\text { followed by a second stent at the level of bronchus } \\
\text { intermedius }\end{array}$ & 0 & 0 & $\begin{array}{l}100 \\
\text { (12 month } \\
\text { follow up) }\end{array}$ \\
\hline $\begin{array}{l}\text { Regnard } \\
1999\end{array}$ & 8 & 7 & 1 & $1,5(0.25-10)$ & $\begin{array}{l}\text { Tracheobronchial stents in } 2 \text { and mediastinum } \\
\text { repositioning in } 5 \text { (tissue expanders). One patient } \\
\text { (left PPS) remained only under follow up }\end{array}$ & 50 & 25 & 50 \\
\hline $\begin{array}{l}\text { Valji } \\
1998\end{array}$ & 5 & 4 & 1 & $0.5(0.3-9)$ & $\begin{array}{l}\text { Mediastinal repositioning and silicone prosthesis. } \\
\text { Mobilization of the mediastinum, anterior } \\
\text { pericardioraphy and anchoring to the parasternal } \\
\text { chest wall }\end{array}$ & 0 & 0 & 100 \\
\hline $\begin{array}{l}\text { Makare } \\
\text { van Maurik } \\
2007\end{array}$ & 20 & 19 & $\begin{array}{l}1 \text { with right } \\
\text { aortic arch }\end{array}$ & $(0.3-15)$ & Extrapleural implantation of expandable prosthesis & 32 & 0 & 60 \\
\hline $\begin{array}{l}\text { Shen } \\
2008\end{array}$ & 18 & 13 & 5 & $7.5(1.1-54.8)$ & $\begin{array}{l}\text { Mediastinum repositioning by inserting saline filled } \\
\text { breast prostheses. Bronchial stenting advocated } \\
\text { in presence of malacia }\end{array}$ & 27.8 & 5.6 & 77 \\
\hline $\begin{array}{l}\text { Soll } \\
2009\end{array}$ & 6 & 4 & 2 & $0.9(0.6-1.2)$ & $\begin{array}{l}\text { Mediastinum repositioning and silicone prosthesis } \\
\text { implantation in } 4 \text { patients. In } 1 \text { patient the } \\
\text { mediastinum was fixed with a pericardial patch. } \\
\text { It was removed due to infection after } 5 \text { mo. } \\
\text { One patient was treated with an adjustable tissue } \\
\text { expander that was replaced by silicone 4y later }\end{array}$ & 33.3 & 0 & 100 \\
\hline Ng 2009 & 1 & 1 & 0 & 0.7 & $\begin{array}{l}\text { Thoracoscopic treatment - Adhesion } \\
\text { Lysis - Mediastinal repositioning }\end{array}$ & 0 & 0 & 100 \\
\hline $\begin{array}{l}\text { 18Partington } \\
2010\end{array}$ & 1 & 0 & 1 & 0.6 & $\begin{array}{l}\text { Mediastinum repositioning and two silicone-walled } \\
\text { breast implants were used as expanders. } \\
\text { Treatment of serious pulmonary vein obstruction } \\
\text { due to compression from the mediastinal shift }\end{array}$ & 0 & 0 & 100 \\
\hline $\begin{array}{l}\text { 19McRae } \\
2011\end{array}$ & 1 & 1 & 0 & $\sim 8 \mathrm{y}$ & $\begin{array}{l}\text { Mediastinal re-orientation accomplished by placing } \\
\text { two breast implants. } 4 \text { months later symptoms } \\
\text { recurred and a durable custom expander with } \\
\text { higher wall thickness was placed }\end{array}$ & $\begin{array}{l}0 \text { after } \\
\text { second } \\
\text { surgery }\end{array}$ & 0 & 100 \\
\hline $\begin{array}{l}\text { 20Jung } \\
2016\end{array}$ & 10 & $\begin{array}{c}4 \text { plus } 3 \\
\text { ppn like s }\end{array}$ & 3 & $1,1(0.6-48.4)$ & $\begin{array}{l}\text { Mediastinal repositioning and multiple saline } \\
\text { filled tissue expander implantation }\end{array}$ & 40 & 0 & 90 \\
\hline
\end{tabular}

*Interval (y) median (min-max): The minimum, maximum and median number of years between lung surgery and the onset of the syndrome.

We could categorize the available treatment options in: i) noninvasive, such as NIMV [3,7]; ii) minimally invasive, such as the placement of endobronchial stents [13-15]; and iii) surgical ones which are the standard of treatment but have high risk of complications [1,4,8-12]. Surgical treatment with volume expanders at the affected hemithorax to re-establish the anatomical position of the mediastinum even many years after pneumonectomy are today the main surgical intervention proposed with good results $[3,4,8,10,16]$. Management for post lobectomy syndrome with implantation of 2 intrathoracic inflatable mammary implants has been reported [17]. This entity is not well defined.

Endobronchial silicone or hybrid stent placement is an alternative approach that minimizes the operative risk, and is applicable in patients not candidates for surgical treatment due to reduced performance status and limited respiratory reserve. In the first presented case, the initial stent inserted was apparently undersized and thus migrated and failed to re-establish airway patency. The straight studded silicone stent inserted in the second intervention adapted better to the bronchial wall and helped resolving the symptoms. NIMV could serve as a "pneumatic stent" keeping the airways patent until placing an endobronchial stent or during the preoperative preparation of the patient as a bridge for surgery in specific cases.

\section{Conclusions}

PPS and PLS are rare complications of right and left pneumonectomy and/or lobectomy. Thorax CT scan and dynamic bronchoscopy are warranted for firm diagnosis. Treatment options range from conservative measures and NIMV or placement of endobronchial stents to extensive surgical interventions and use of volume expanders. Multi-disciplinary discussions and comprehensive assessment of each individual case is crucial to establish the treatment strategy. 


\section{References}

1. Grillo HC, Shepard JO, Mathisen DJ, Kanarek DJ. Postpneumonectomy syndrome: diagnosis, management, and results. Ann Thorac Surg 1992;54:638-51.

2. Wasserman K, Jamplis RW, Lash H, et al. Post-pneumonectomy syndrome. Surgical correction using Silastic implants. Chest 1979;75: 78-81.

3. Murgu SD, Colt HG. A 68 year-old man with intractable dyspnea and wheezing 45 years after a pneumonectomy. Chest 2006;129: 1107-11.

4. Valji AM, Maziak DE, Shamji FM, Matzinger FR. Postpneumonectomy syndrome: recognition and management. Chest 1998;114(6): 1766-9.

5. Boiselle PM, Feller-Kopman D, Ashiku S, et al. Tracheobronchomalacia: evolving role of dynamic multislice helical CT. Radiol Clin North Am 2003; 41(3): 627-36.

6. Carden KA, Boiselle PM, Waltz DA, Ernst A. Tracheomalacia and tracheobronchomalacia in children and adults: an in-depth review. Chest 2005; 127:984-1005

7. Murgu SD, Colt HG. Tracheobronchomalacia and excessive dynamic airway collapse. Respirology 2006;11(4):388-406.

8. Macaré van Maurik AF., Stubenitsky BM., van Swieten HA., et al. Use of tissue expanders in adult postpneumonectomy syndrome $\mathrm{J}$ Thorac Cardiovasc Surg 2007;134:608-12.
9. Shen KR, Wain JC, Wright CD, et al. Post-pneumonectomy syndrome: surgical management and long-term results. J Thorac Cardiovasc Surg 2008;135:1210-6; discussion 1216-9.

10. Jung JJ, Cho JH, Kim HK, et al. Management of post-pneumonectomy syndrome using tissue expanders. Thorac Cancer 2016;7:88-93.

11. Ng T, Ryder BA, Maziak DE, Shamji FM. Thoracoscopic approach for the treatment of postpneumonectomy syndrome. Ann Thorac Surg 2009;88:1015-8.

12. Matthew CM, Detterbeck FC, Narayan D. Correction of postpneumonectomy syndrome using a custom implant. BMJ Case Rep 2011; pii:bcr1120103523.

13. Cordova FC, Travaline JM, O'Brien GM. Treatment of left pneumonectomy syndrome with expandable endobronchial prosthesis. Chest 1996;109:567-70.

14. Moser NJ, Woodring JH, Wolf KM. Management of postpneumonectomy syndrome with a bronchoscopically placed endobronchial stent. South Med J 1994;87:1156-9.

15. Jansen JP, Brutel de la Rivière A, et al. Postpneumonectomy syndrome in adulthood. Surgical correction using an expandable prosthesis. Chest 1992;101:1167-70.

16. Soll C, Hahnloser D, Frauenfelder T, et al. The postpneumonectomy syndrome: clinical presentation and treatment. Eur J Cardiothorac Surg 2009;35:319-24.

17. Heyndrickx M, Le Rochais JP, Flais F, Lemennais Y. Postpneumonectomy-like syndrome after lobectomy: An exceptional situation. Asian Cardiovasc Thorac Ann 2015; 23:464-6. 